\title{
Radiation-damage investigation of a DNA 16-mer
}

\section{Valéria Bugris, Veronika Harmat, Györgyi Ferenc, Sándor Brockhauser, Ian Carmichael and Elspeth F. Garman}

J. Synchrotron Rad. (2019). 26, 998-1009

\section{IUCr Journals CRYSTALLOGRAPHY JOURNALS ONLINE}

Copyright (C) International Union of Crystallography

Author(s) of this article may load this reprint on their own web site or institutional repository provided that this cover page is retained. Republication of this article or its storage in electronic databases other than as specified above is not permitted without prior permission in writing from the IUCr.

For further information see http://journals.iucr.org/services/authorrights.html 


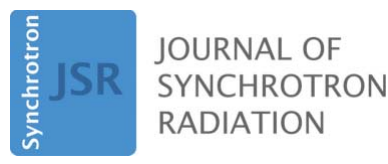

ISSN 1600-5775

Received 15 February 2019

Accepted 25 May 2019

Edited by M. Weik, Institut de Biologie Structurale, France

Keywords: DNA; radiation damage; global damage; specific damage.

PDB references: DNA 16-mer, absorbed dose 0.48 MGy, 6qt1; absorbed dose 6.2 MGy, 6qt2; absorbed dose 12.0 MGy, 6qt3; absorbed dose 17.7 MGy, 6qt4; absorbed dose 23.5 MGy, 6qt5; absorbed dose 29.2 MGy, 6qt6

Supporting information: this article has supporting information at journals.iucr.org/s

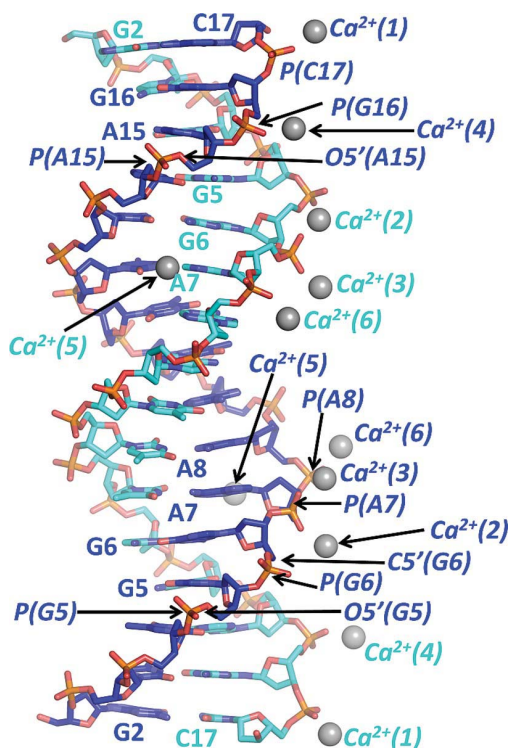

(C) 2019 International Union of Crystallography

\section{Radiation-damage investigation of a DNA 16-mer}

\author{
Valéria Bugris, ${ }^{\text {a,b }}$ Veronika Harmat, ${ }^{a, c}$ Györgyi Ferenc, ${ }^{\text {d }}$ Sándor Brockhauser, ${ }^{a, e}$ \\ Ian Carmichael ${ }^{f}$ and Elspeth F. Garman ${ }^{\text {b* }}$ \\ ${ }^{a}$ X-ray Crystallography Laboratory, Biological Research Centre, HAC-BRC, Temesvári krt. 62, Szeged 6726, Hungary, \\ ${ }^{\mathbf{b}}$ Department of Biochemistry, University of Oxford, South Parks Road, Oxford OX1 3QU, UK, 'caboratory of Structural \\ Chemistry and Biology and MTA-ELTE Protein Modeling Research Group, Eötvös Loránd University, Budapest, Hungary, \\ dNucleic Acid Synthesis Laboratory, Biological Research Centre, HAC-BRC, Temesvári krt. 62, Szeged 6726, Hungary, \\ eEuropean X-ray Free-Electron Laser Facility GmbH (EuXFEL), Holzkoppel 4, 22869 Schenefeld, Germany, and \\ ${ }^{f}$ Notre Dame Radiation Laboratory, University of Notre Dame, Notre Dame, IN 46556, USA. \\ ${ }^{*}$ Correspondence e-mail: elspeth.garman@bioch.ox.ac.uk
}

In macromolecular crystallography, a great deal of effort has been invested in understanding radiation-damage progression. While the sensitivity of protein crystals has been well characterized, crystals of DNA and of DNA-protein complexes have not thus far been studied as thoroughly. Here, a systematic investigation of radiation damage to a crystal of a DNA 16-mer diffracting to $1.8 \AA$ resolution and held at $100 \mathrm{~K}$, up to an absorbed dose of $45 \mathrm{MGy}$, is reported. The RIDL (Radiation-Induced Density Loss) automated computational tool was used for electron-density analysis. Both the global and specific damage to the DNA crystal as a function of dose were monitored, following careful calibration of the X-ray flux and beam profile. The DNA crystal was found to be fairly radiation insensitive to both global and specific damage, with half of the initial diffraction intensity being lost at an absorbed average diffraction-weighted dose, $D_{1 / 2}$, of $19 \mathrm{MGy}$, compared with $9 \mathrm{MGy}$ for chicken egg-white lysozyme crystals under the same beam conditions but at the higher resolution of $1.4 \AA$. The coefficient of sensitivity of the DNA crystal was $0.014 \AA^{2} \mathrm{MGy}^{-1}$, which is similar to that observed for proteins. These results imply that the significantly greater radiation hardness of DNA and RNA compared with protein observed in a DNA-protein complex and an RNAprotein complex could be due to scavenging action by the protein, thereby protecting the DNA and RNA in these studies. In terms of specific damage, the regions of DNA that were found to be sensitive were those associated with some of the bound calcium ions sequestered from the crystallization buffer. In contrast, moieties farther from these sites showed only small changes even at higher doses.

\section{Introduction}

X-ray crystallography gives a space- and time-averaged structure of a macromolecule. It is currently the major technique used to solve such structures to near-atomic-level resolution (ångström resolution). By solving the structure of the macromolecules/complexes of interest, an understanding of the likely modes of action can be gained and questions about their function can be answered. In order to be able to provide detailed explanations for the function, reaction mechanism or interactions in question, excellent structure quality is needed. Thus, crystallographic method development allowing accurate structure determination is vital.

A major limitation of X-ray crystallography is that the majority of absorbed X-rays (rather than the elastically scattered minority which provide the desired diffraction pattern) damage the fragile macromolecular crystals, which can hinder structure determination or result in flawed biolo- 
gical interpretations [for example for bacteriorhodopsin (Matsui et al., 2002) and xylose isomerase (Taberman et al., 2019); for a review, see Garman \& Weik (2017)].

Radiation damage to the sample is caused by the absorption of photons from the beam either via the photoelectric effect (total absorption of the photon followed by the ejection of an inner shell electron and the subsequent emission of an Auger electron or fluorescent X-ray depending on the atomic number of the affected atom) or via momentum transfer through Compton scattering (inelastic scattering of the photon, which then escapes following a varying amount of energy loss to an atomic electron, which may also be ejected). At the incident X-ray energies $\left(E_{\text {inc }}\right)$ normally used in macromolecular crystallography (MX), the photoelectric effect has a much higher cross-section and dominates the interaction, at $E_{\text {inc }}=12.4 \mathrm{keV}$ accounting for over $90 \%$ (for a $100 \mu \mathrm{m}$-thick non-metal-containing crystal) of the energy deposited by the beam (Garman, 2010). Typically, each released photoelectron has enough energy to induce up to 500 further ionizations, which in turn can result in the formation of radical species throughout the crystal. In macromolecular crystals, the presence of $20-80 \%$ solvent makes the radiolysis of this fraction a major contributor to the subsequent creation of these potentially deleterious species (O'Neill et al., 2002). Some of the energy deposited by the beam during these processes is converted into heat, which may induce a temperature rise in the sample (Snell et al., 2007; Warren et al., 2019). The diffracted photons, in contrast, are scattered elastically and thus do not contribute to the damage.

A wide literature has accumulated which addresses various aspects of radiation-damage progression, and highlights the reasons why crystallographers should be aware of this issue and adopt methods to minimize its effects (Garman \& Owen, 2006; Ravelli \& Garman, 2006; Holton, 2009). Radiationdamage effects are usually separated into two categories based on their different characteristics. Global damage is observed in reciprocal space in the diffraction pattern often as an overall loss of reflection intensities, a loss of resolution, unit-cell volume expansion and usually increasing mosaicity. These phenomena have been well characterized and dose limits have been suggested, such as the experimental dose limit (determined for data to $2.2 \AA$ resolution) of $30 \mathrm{MGy}$ [1 Gy (gray) = $1 \mathrm{~J} \mathrm{~kg}^{-1}$; energy absorbed/mass] at $100 \mathrm{~K}$ (subsequently denoted cryo-) beyond which data are likely to be compromised (Owen et al., 2006; Nave \& Garman, 2005). In general, for cryo-cooled protein crystals every additional absorbed dose increment of approximately $10 \mathrm{MGy}$ results in a loss of about $1 \AA$ resolution in the diffraction pattern and thus also in the final structure (Howells et al., 2009).

Specific damage involves radiation-induced chemical and conformational changes in macromolecular structures (Helliwell, 1988). It is observed to occur in a reproducible order in protein crystals: first metallo-centres are reduced and disulfide bonds are cleaved, followed by the decarboxylation of acidic residues and then methionine $\mathrm{C}-\mathrm{S}$ bond cleavage (Ravelli \& McSweeney, 2000; Weik et al., 2000; Burmeister, 2000). Previously, an additional manifestation of specific damage had been suggested to be $-\mathrm{OH}$ cleavage from tyrosine residues (Burmeister, 2000). However, it was subsequently shown that the observed electron-density loss round this - $\mathrm{OH}$ group was instead due to movement of the entire tyrosine ring (Bury et al., 2017).

Crystallographic investigations of X-ray radiation-induced changes in MX to nucleic acid crystals themselves and the larger class of nucleoprotein complexes are generally less comprehensive, and a specific damage 'pecking order' for them has not yet been established. Nucleic acid and nucleoprotein complexes now (as of 6 February 2019; https:// www.rcsb.org/stats/summary) comprise approximately $6.34 \%$ of MX-derived structures deposited within the Protein Data Bank (PDB). While systematic radiation-damage studies on crystals of an RNA-protein complex (Bury, McGeehan et al., 2016) and a DNA-protein complex (Bury et al., 2015) have already been reported in detail, to our knowledge no comparable investigations have been performed on crystals containing only DNA, which would allow a direct comparison with previous work.

The impact of ionizing radiation on DNA has been investigated under a wide variety of experimental conditions. Among the most relevant to the present study are those conducted in glassy matrices at $77 \mathrm{~K}$, involving the search, by electron paramagnetic resonance spectroscopy, for the radical species that are eventually formed following the initial ionization and excitation events (Becker \& Sevilla, 1993; Becker et al., 2007). X-ray damage has also been observed during the course of X-ray photoelectron spectroscopic (XPS) investigations of nucleic acids deposited on a surface under vacuum (Ptasińska \& Sanche, 2007), and the nature of some of the damage sites could be determined directly from the measured XPS signals. Efforts to probe the direct effect of low-energyelectron interactions by dissociative electron attachment to isolated, immobilized DNA molecules on surfaces under vacuum conditions (Boudaïfa et al., 2000) are also of importance and results have been reviewed more recently (Alizadeh \& Sanche, 2014; Alizadeh et al., 2015). However, solutionphase studies have tended to focus on the consequences of hydroxyl radical attack in aqueous room-temperature media (Michael \& O’Neill, 2000; Cadet et al., 1999; SpotheimMaurizot \& Davídková, 2011). While no doubt biologically relevant, the effects of this particular reactive species are of less interest here since hydroxyl radicals are assumed to be immobile at $100 \mathrm{~K}$ (Owen et al., 2012), the temperature used for the study reported here. Cellular DNA, which is mainly in the $\mathrm{B}$ form (base pairs perpendicular to the helix axis), has around 20 water molecules per nucleotide in the first two hydration layers, and this drastically modifies the yield of base lesions when DNA is damaged at both low temperature and room temperature (Yokoya et al., 2002). Note that in the DNA literature, holes produced by ionization events in this hydration layer are incorporated into the classification as direct damage, with the hole being thought to transfer promptly to the DNA (Swarts et al., 2007).

Double-brominated DNA crystals have been probed using Raman micro-spectroscopy, showing radiation-damage- 
induced changes. The researchers identified breakages of a single carbon-bromine covalent bond by both MX and Raman techniques and potentially other damage to DNA, but they were not able to completely assign all of the signals (McGeehan et al., 2007). A better appreciation of the mechanisms involved may eventually allow the manipulation of the effects of ionizing radiation at the molecular level (McGeehan et al., 2007).

Structural studies on DNA and RNA and complexes with proteins have been widely reported (Berman et al., 2000), with over 10000 entries now in the PDB: $78.6 \%$ of these were solved by $\mathrm{MX}$, of which $86 \%$ were at cryo-temperatures. However, as noted above, no systematic radiation-damage MX investigation has been published which shows specific changes within the native DNA and/or RNA molecule. This may be related to the fact that DNA itself is a relatively stable molecule (Halliwell \& Gutteridge, 1998). Radiation chemists and biologists have studied DNA in solution because it is the macromolecule responsible for the exchange of genetic information, and its stability and radiation resistance have direct consequences for human health (Michael \& O'Neill, 2000; Kempner, 1993; Halliwell \& Gutteridge, 1998). There is of course a wide range of literature on DNA damage induced by different qualities of ionizing radiation, including studies on the effect of low-linear energy transfer radiations particularly targeted at the biological function of DNA (Kadhim et al., 2006). Although these investigations have uncovered important mechanistic details, a complete picture has yet to emerge.

Using X-ray diffraction data collected at $100 \mathrm{~K}$ from a crystal of a protein-RNA complex (TRAP-RNA), the specific damage incidence for both the protein and RNA components (91 kDa amino acids and 53 base pairs, respectively) of a biologically relevant complex over a large dose range (2.07$44.63 \mathrm{MGy}$ ) has previously been reported (Bury, McGeehan et al., 2016). The RNA appeared to be far less susceptible to radiation damage than was the protein. Interestingly, the amino acids in contact with RNA suffered lower levels of damage compared with those which were more remote, implying some radioprotection of the protein by the RNA (Bury, McGeehan et al., 2016). Another $100 \mathrm{~K}$ study on a crystal of a DNA-protein complex with similar numbers of DNA and protein atoms (382 amino acids, 2496 protein non-H atoms; 35 DNA base pairs, 1429 DNA atoms) again showed greater resistance of the nucleic acid component than the protein to radiation damage (Bury et al., 2015). Together, these results suggest a lower susceptibility of nucleotides than proteins to radiation damage, although the possibility that the nucleotides are protected by the protein cannot be excluded.

In the systematic study that we report here, our objective was to investigate the specific and global radiation-damage mechanisms in DNA crystals harbouring no protein component. By collecting a dose series from a crystal of a DNA 16mer, we have characterized the specific damage by using an automated tool called RIDL (Radiation-Induced Density Loss) to analyse the electron-density loss (Bury \& Garman, 2018). RIDL has been developed to enable the objective detection and quantification of radiation-induced site-specific changes to macromolecular structures as a function of absorbed dose. The program has been designed to extract suitable per-atom descriptors of radiation damage, based on the changes detectable in the structure-factor $F_{\mathrm{obs}, n}-F_{\mathrm{obs}, 1}$ Fourier difference maps through successive dose data sets (numbered 1 to $n$ ). The metrics derived using RIDL (Bury \& Garman, 2018), a computer program that is described below, previously enabled this comparative analysis of specific radiation damage in disparate systems (Bury, Carmichael et al., 2016).

Here, a comprehensive analysis of radiation damage to the 16-mer DNA crystal is presented, including results for the diffraction intensity decay, unit-cell volume expansion and relative isotropic $B$-factor increase with dose, as well as an analysis of the various sites of specific radiation damage in the DNA and the rise in atomic $B$ factors during the experiment.

\section{Materials and methods}

\subsection{Synthesis and annealing of DNA duplexes}

The 16-mer DNA oligonucleotide was synthesized using a DNA/RNA/LNA H-16 synthesiser (K\&A Laborgeraete) by standard $\beta$-cyanoethyl phosphoramidite chemistry at a nominal scale of $0.2 \mu \mathrm{mol}$. The sequence of the oligonucleotide was 5'-GCTGGAAATTTCCAGC-3' (G, guanine; C, cytosine; $\mathrm{T}$, thymine; $\mathrm{A}$, adenine). The oligonucleotide was purified by HPLC on an RP-C18 column under ion-pairing conditions [using mobile phases containing $0.1 \mathrm{~m} M$ triethylammonium acetate (TEAA) pH 6.5 buffer]. The 4,4'-dimethoxytrityl protective group was removed from the $5^{\prime}$-end of the oligonucleotide using 2\% TFA on a Poly-Pak column. After lyophilization, the DNA was resuspended in $5 \mathrm{mM}$ HEPES pH 6.6 at a concentration of $1.5 \mathrm{mM}$, and the selfcomplementary strands were annealed by heating to $80^{\circ} \mathrm{C}$ followed by slow cooling to $25^{\circ} \mathrm{C}$. The solution of the DNA duplex was immediately used for crystallization.

\subsection{Crystallization}

Crystals were grown in a reproducible fashion using the hanging-drop vapour-diffusion method with $2 \mu 11.5 \mathrm{mM}$ DNA solution ( $5 \mathrm{~m} M$ HEPES pH 6.6) plus $2 \mu 110 \mathrm{~m} M$ HEPES $\mathrm{pH}$ 6.6 plus $4 \mu \mathrm{l}$ reservoir solution equilibrated against a reservoir consisting of $1 \mathrm{ml} \mathrm{34 \%} \mathrm{PEG} \mathrm{200,} 600 \mathrm{~m} M \mathrm{CaCl}_{2}$ and $10 \mathrm{mM}$ HEPES $\mathrm{pH}$ 8.6. The conditions were optimized from those previously reported for the crystallization of the 17-mer DNA sequence containing an extra cytosine at its $5^{\prime}$ end (Huang et al., 2005; PDB entry 1sgs) and the same 16-mer as suggested by McGeehan et al. (2007) and Brockhauser et al. (2008). Crystals were visible after a day and grew to approximate dimensions of $300 \times 35 \times 15 \mu \mathrm{m}$ within 3-5 days (Fig. 1). These DNA crystals were used for data collection at $100 \mathrm{~K}$ without added cryoprotectant since the PEG 200 in the crystallization buffer was sufficient for cryoprotection. 


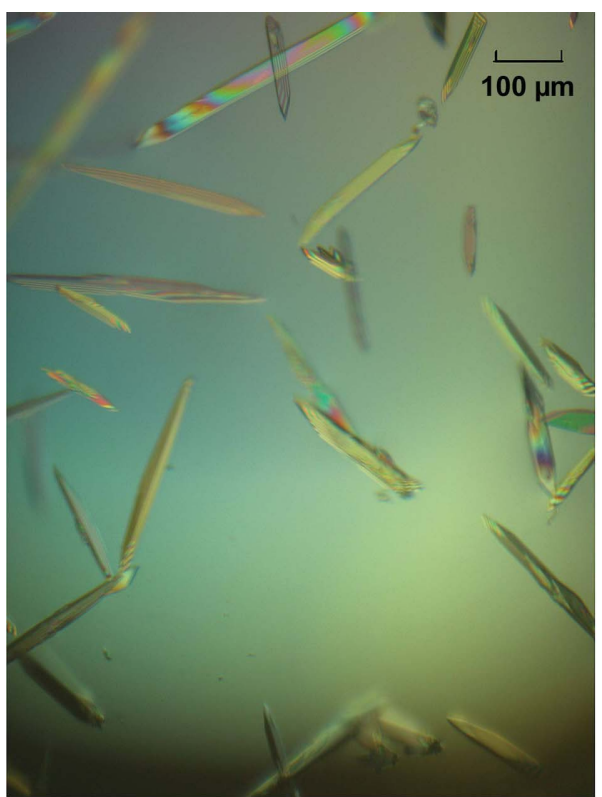

(a)

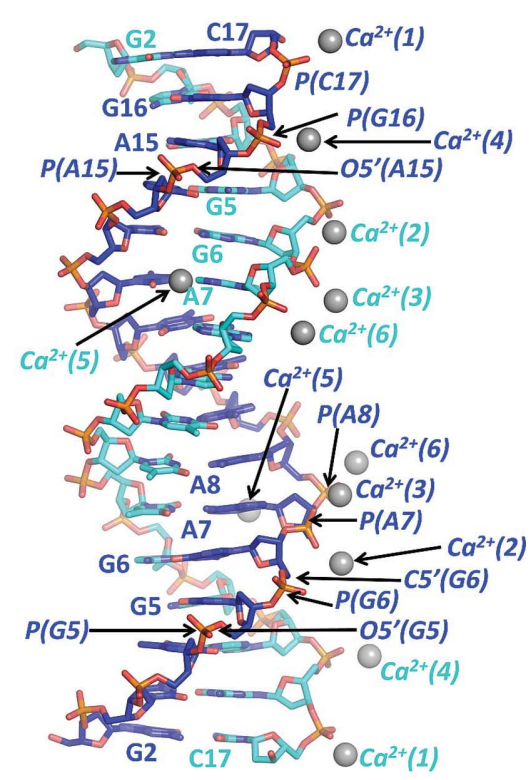

(b)

5'- G2 C3 T4 G5 G6 A7 A8 A9 T10 T11 T12 C13 C14 A15 G16 C17- 3' $\begin{array}{llllllllllllllll}\text { I } & \text { I } & \text { I } & \text { I } & \text { I } & \text { I } & \text { I } & \text { I } & \text { I } & \text { I } & \text { I } & \text { | } & \text { I } & \text { I } & \text { I } & \text { I }\end{array}$ 3'- C17 G16 A15 C14 C13 T12 T11 T10 A9 A8 A7 G6 G5 T4 C3 G2- 5'

(c)

Figure 1

(a) The 16-mer DNA crystals and $(b)$ the final structure of the double helix of the DNA segment. In (b) atoms are shown as follows: carbon, sky blue and blue for different DNA chains; phosphorus, orange; oxygen, red; nitrogen, dark blue. Nucleotides are labelled $\mathrm{G}, \mathrm{A}, \mathrm{T}$ and $\mathrm{C}$ and individual atoms are labelled in italics, with the nucleotide ID in parentheses. $\mathrm{Ca}^{2+}(1), \mathrm{Ca}^{2+}(2)$ and $\mathrm{Ca}^{2+}(3)$ all lie on a vertical threefold axis and have 1/3 occupancy each. (c) The 2D structure of the duplex of the DNA 16-mer [note that the numbering is as used in Huang et al. (2005) so that the sequence starts at nucleotide 2].

\subsection{Beam calibration}

Data were collected on beamline I24 at Diamond Light Source (DLS). Before data collection, the X-ray flux and beam profile were calibrated as described below to enable the recovery of accurate information for the dose calculations.

To determine the beam flux (the number of photons per unit time) a diode linked to a picoammeter was used, as described previously (Owen et al., 2009). The $500 \mu \mathrm{m}$-thick silicon PIN diode (Canberra, model No. PD300-500CB) was placed at the crystal position and the diode current was measured and converted into photons $\mathrm{s}^{-1}$ using the appropriate pre-determined relationship.

A calibrated metal edge and the same silicon pin diode were used to profile the horizontal and vertical beam profiles. The edge was moved through the beam in order to obscure increasing amounts of the beam, and the current produced by the remaining X-rays was recorded after each move. Data collected in both directions (vertical and horizontal) were plotted and the full widths at half-maximum (FWHM) were calculated using a DLS beamline software utility which took the derivative of the edge-scan measurements. The beam had an approximately 'top-hat' profile with an FWHM of $52.7 \mu \mathrm{m}$ in the horizontal direction and a $50 \mu \mathrm{m}$ FWHM Gaussian shape in the vertical plane (Fig. 2).

\subsection{Data collection}

Data were collected at $100 \mathrm{~K}$ using a wavelength of $0.9686 \AA(12.8 \mathrm{keV})$ and a PILATUS3 6M detector at a crystalto-detector distance that gave a resolution of $2 \AA$ at the largest inscribed circle on the detector face. 48 complete data sets were collected from one position of the DNA crystal $(35 \times 279 \times 15 \mu \mathrm{m})$ using identical experimental protocols. The flux was $3.52 \times 10^{11}$ photons s $^{-1}$ (at $10 \%$ transmission).

From the DNA crystal (space group H32), four successive runs of 12 data sets (one run $=720^{\circ}$ rotation, one data set $=60^{\circ}$ ) were collected (oscillation of $0.1 \%$ image with $10 \%$ beam transmission and an exposure time of $0.02 \mathrm{~s}$ ). The maximum resolution obtained was $1.8 \AA$ A (Table 1).

Radiation-damage data-set series were also collected under identical beam conditions from two native chicken egg-white lysozyme crystals as a cross-check on the dose estimates and beam calibrations, since the resolutiondependent intensity decay of lysozyme at $100 \mathrm{~K}$ has been previously characterized by a number of research groups. The doses to reduce the initial diffraction intensity to half for various resolution shells (Teng \& Moffat, 2000) and for the total diffraction intensity to fall to half of its initial value (see, for example, Teng \& Moffat, 2002; de la Mora et al., 2011) at various resolutions have both been determined.

\subsection{Dose calculation}

In order to reliably interpret the $\mathrm{X}$-ray radiation-damage data, it is important to have an accurate estimate of the absorbed X-ray dose. RADDOSE-3D (Zeldin, Gerstel et al., 2013) was used to calculate the dose distributions after the first [Fig. 3(a)], the 12th [Fig. 3(b)], the 24th [Fig. 3(c)] and the 48th [Fig. 3(d)] data sets, so that the progression of damage events could be associated with the corresponding dose differences.

The beam-intensity profiles (Fig. 2) were found to be approximately top-hat (horizontally) and Gaussian (vertically), but $R A D D O S E-3 D$ allows either top-hat in both directions or Gaussian in both directions (as well as taking a $2 \mathrm{D}$ experimentally measured profile if available). Thus, the beam was modelled horizontally as a very broad $1000 \mu \mathrm{m}$ FWHM Gaussian which was collimated to $52.7 \mu \mathrm{m}$ and as a $50.0 \mu \mathrm{m}$ uncollimated $(1000 \mu \mathrm{m}$ collimation aperture used) Gaussian in the vertical direction. The photon flux prior to beam attenuation was measured as $3.52 \times 10^{12}$ photons s $^{-1}$ and was constant throughout the experiment. The calculation of the crystal absorption coefficients in $R A D D O S E-3 D$ 


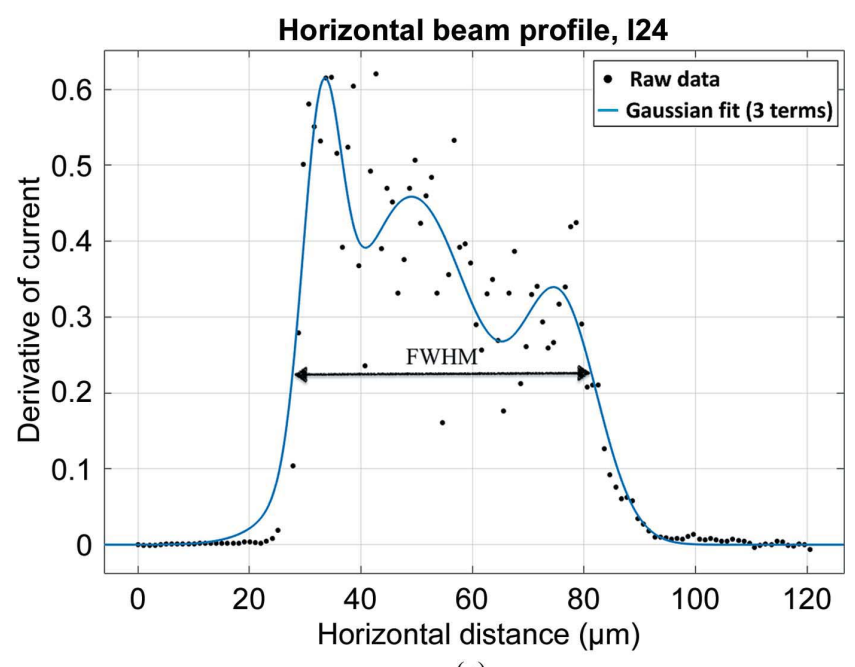

(a)

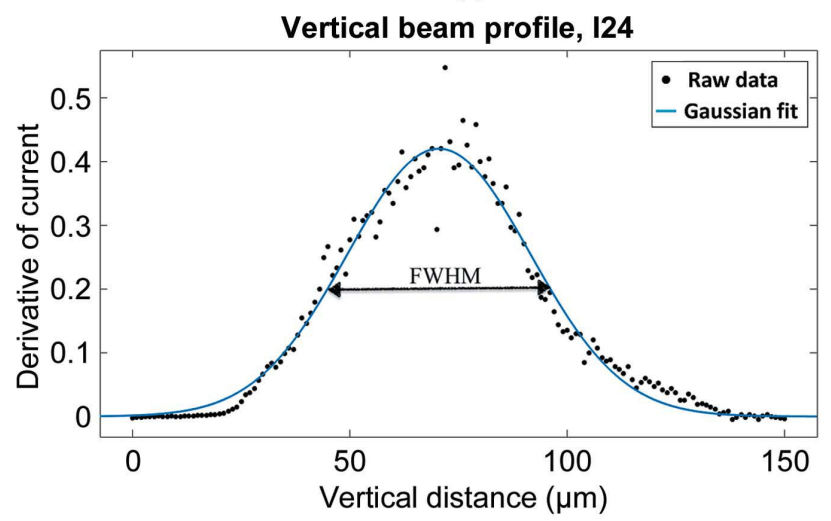

(b)

Figure 2

Beam-profile calibration on the I 24 beamline at DLS. The FWHMs of the beam profiles are shown: (a) $52.7 \mu \mathrm{m}$ approximately top-hat profile horizontally and (b) $50.0 \mu \mathrm{m}$ Gaussian vertically. included the water and the heavy-atom content from the crystallization conditions (the sulfur from the HEPES buffer and the calcium and chlorine from the $\mathrm{CaCl}_{2}$ ). All of the results on radiation-damage progression were plotted against the resulting average diffraction-weighted dose (DWD; Zeldin, Brockhauser et al., 2013) values (the average DWD for each data set is added to the cumulative total dose for each preceding data set to obtain the dose at that point in the experiment).

\subsection{Data processing}

Diffraction data were processed with DIALS (Sauter et al., 2013; Winter et al., 2018) and the CCP4 package (Winn et al., 2011) using CCP4i2 (Potterton et al., 2018), including AIMLESS (Evans \& Murshudov, 2013) and POINTLESS (Evans, 2006). The first data set (low-dose data set) from the crystal was used to obtain phases by molecular replacement (MR) in Phaser (McCoy et al., 2007), using the structure containing one extra nucleotide (Huang et al., 2005; McGeehan et al., 2007; PDB entry 1sgs) as the search model. Note that as a result of using this MR model and to avoid confusion, we have retained the same nucleotide numbering in the 16-mer studied here, so that it starts at G2 and ends at C17. The structure was refined in REFMAC5 (Murshudov et al., 2011) using TLS and restrained refinement, with the DNA segment as a single TLS group. Individual atomic $B$ factors were refined and $5 \%$ of the reflections were withheld for use in $R_{\text {free }}$. Manual model building was carried out using Coot (Emsley et al., 2010).

The final model contains 16 nucleotide residues and 38 water molecules (two of them in alternate positions) as well as six $\mathrm{Ca}^{2+}$ ion positions three fully occupied sites $\left[\mathrm{Ca}^{2+}(4)\right.$ to $\left.\mathrm{Ca}^{2+}(6)\right]$ with an additional three $\mathrm{Ca}^{2+}$ ions sitting on a crystallographic threefold axis each with $1 / 3$ occupancy $\left[\mathrm{Ca}^{2+}(1)\right.$ to $\left.\mathrm{Ca}^{2+}(3)\right]$, giving a total of four calcium ions per DNA monomer for the dose calculations\}. The DNA double helix is created by crystallographic twofold rotation. To create models from the higher-dose data sets (dose greater than the first data set), the final model from the first data set was used and further refined using REFMAC5 against the structure factors output by AIMLESS for the higherdose data sets (restrained coordinate and individual $B$-factor refinement, with $\mathrm{H}$ atoms generated). The structures refined against data sets with absorbed doses of $0.48,6.2,12.0,17.7,23.5$ and 29.2 MGy have been deposited in the PDB as entries 6qt1, 6qt2, 6qt3, 6qt4, $6 q t 5$ and 6qt6, respectively. For the analyses, the resolution cutoff for all data sets was $1.8 \AA$. However, the esti-
Figure 3

(a)

(a) The DNA crystal within the loop during data collection. The inset in $(a),(b),(c)$ and $(d)$ are online RADDOSE-3D (Zeldin et al., 2013) calculations of dose distributions in the cuboid-shaped crystal after the ( $a$, inset) first (DWD: $0.48 \mathrm{MGy}),(b)$ 12th (12.0 MGy), (c) 24th (23.5 MGy) and (d) 48th (45.5 MGy) data sets. The dose isosurfaces are drawn at $0.1 \mathrm{MGy}$ (white), $20 \mathrm{MGy}$ (blue) and 30 MGy (dark red). 
Table 1

Crystallographic data-collection, processing and structure-refinement statistics for the DNA crystal at $100 \mathrm{~K}$ in space group $H 32$.

Data were collected on beamline I24 at Diamond Light Source $\left(\lambda=0.9686 \AA \AA\right.$; incident flux $3.52 \times 10^{11}$ photons s $\left.{ }^{-1}\right)$. The data-collection protocol involved eight full $360^{\circ}$ rotations of the crystal. Each full rotation was divided into six wedges of $60^{\circ}$ each, resulting in 48 data sets (the exposure time for each data set was $12 \mathrm{~s}$ ). Structures were refined against data sets processed to $1.8 \AA$ resolution. Values in parentheses are for the outer resolution shell.

\begin{tabular}{|c|c|c|c|c|c|c|}
\hline Data set & 1 & 7 & 13 & 19 & 25 & 31 \\
\hline PDB code & $6 \mathrm{qt} 1$ & $6 \mathrm{qt} 2$ & $6 \mathrm{qt} 3$ & $6 \mathrm{qt} 4$ & $6 \mathrm{qt} 5$ & $6 q t 6$ \\
\hline \multicolumn{7}{|l|}{ Data collection } \\
\hline Cumulative dose (average DWD) (MGy) & 0.48 & 6.2 & 12.0 & 17.7 & 23.5 & 29.2 \\
\hline \multicolumn{7}{|l|}{ Data processing } \\
\hline \multicolumn{7}{|l|}{ Unit-cell parameters } \\
\hline$a=b(\AA)$ & 36.82 & 36.86 & 36.89 & 36.93 & 36.93 & 36.97 \\
\hline$c(\AA)$ & 161.93 & 162.06 & 162.20 & 162.36 & 162.48 & 162.57 \\
\hline Resolution (Å) & $\begin{array}{l}31.31-1.80 \\
\quad(1.85-1.80)\end{array}$ & $\begin{array}{l}31.34-1.80 \\
\quad(1.85-1.80)\end{array}$ & $\begin{array}{l}31.36-1.80 \\
\quad(1.85-1.80)\end{array}$ & $\begin{array}{l}31.40-1.80 \\
\quad(1.85-1.80)\end{array}$ & $\begin{array}{l}31.40-1.80 \\
\quad(1.85-1.80)\end{array}$ & $\begin{array}{l}31.43-1.80 \\
\quad(1.85-1.80)\end{array}$ \\
\hline$\langle I / \sigma(I)\rangle$ & $9.4(1.0)$ & $8.7(0.9)$ & $5.4(0.3)$ & $3.5(0.2)$ & $2.6(0.1)$ & $1.8(0.0)$ \\
\hline Completeness (\%) & $92.1(59.0)$ & $92.5(60.0)$ & $92.1(56.4)$ & $92.2(56.7)$ & $92.2(57.5)$ & $92.3(57.7)$ \\
\hline Multiplicity & $2.9(2.5)$ & $3.0(2.5)$ & $2.9(2.5)$ & $3.0(2.5)$ & $2.9(2.6)$ & $3.0(2.6)$ \\
\hline$R_{\text {meas }}$ & $0.053(0.959)$ & $0.068(1.288)$ & $0.072(3.470)$ & $0.099(5.447)$ & $0.127(16.7)$ & $0.167(143)$ \\
\hline $\mathrm{CC}_{1 / 2}$ & $0.998(0.608)$ & $0.996(0.318)$ & $0.997(0.153)$ & $0.995(0.237)$ & $0.992(0.190)$ & $0.983(0.0)$ \\
\hline Normalized intensity $\dagger$ & 1 & 0.93 & 0.798 & 0.69 & 0.57 & 0.47 \\
\hline Wilson $B\left(\AA^{2}\right)$ & 36.58 & 38.17 & 40.91 & 51.31 & 60.97 & 68.11 \\
\hline Estimated resolution limit $\$(\AA)$ & 1.80 & 1.80 & 1.89 & 1.97 & 2.17 & 2.30 \\
\hline \multicolumn{7}{|l|}{ Refinement and model quality§ } \\
\hline$R / R_{\text {free }}$ & $0.220 / 0.256$ & $0.220 / 0.282$ & $0.222 / 0.291$ & $0.232 / 0.310$ & $0.248 / 0.345$ & $0.270 / 0.369$ \\
\hline Mean atomic $B$ factor $\left(\AA^{2}\right)$ & 49.35 & 50.01 & 52.57 & 55.10 & 57.18 & 57.75 \\
\hline R.m.s.d., bond lengths $(\AA)$ & 0.011 & 0.0096 & 0.0087 & 0.0085 & 0.0074 & 0.0070 \\
\hline R.m.s.d., bond angles $\left({ }^{\circ}\right)$ & 1.914 & 1.764 & 1.670 & 1.710 & 1.567 & 1.540 \\
\hline
\end{tabular}

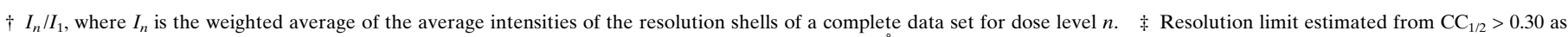

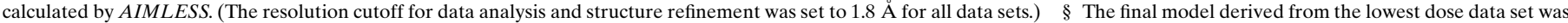

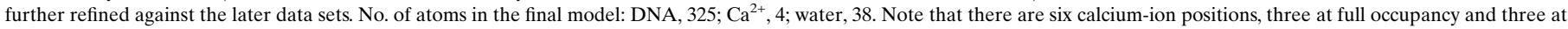
$1 / 3$ occupancy.

mated resolution of the data sets decreases with dose (Table 1, where the resolution limits are estimated using $\left.\mathrm{CC}_{1 / 2}>0.30\right)$. The 35.0 MGy structure was of such poor refined quality ( $R$ and $R_{\text {free }}=0.40$ and 0.46 , respectively) owing to the degradation of the diffraction and low signal to noise at higher resolution in data set 37 that it has not been deposited. Figures showing the structure and electron-density maps were created and drawn using PyMOL (Schrödinger).

\subsection{Specific damage analysis}

As noted above, to simplify the search for specific damage events we used RIDL (Bury \& Garman, 2018). This program calculates per-atom metrics to describe the electron-density changes between complete diffraction data sets collected at successive doses. These data allow the location and frequency of specific damage sites to be investigated on a range of scales from nucleotides to specific atoms, since the cleavage of chemical bonds and disordering of atoms typically leaves a signature of electron-density loss in $F_{\mathrm{obs}, n}-F_{\mathrm{obs}, 1}$ difference maps. These are captured in the present work by the $D_{\text {neg }}$ (atom) metric distribution over all atoms present for every sixth data set. This provides a suitable description of the overall magnitude of electron density lost at an atomic site and is defined as

$$
D_{\text {neg }}(\text { atom })=\frac{\sum_{\nu \in V_{\text {atom }}^{-}}-\rho_{\Delta}(\nu) \cdot \rho_{\text {calc }}(v)}{\sum_{\nu \in V_{\text {atom }}^{-}} \rho_{\text {calc }}(\nu)},
$$

where $\rho_{\Delta}(\nu)$ is the difference density map, $F_{\text {obs }, n}-F_{\text {obs, } 1}$, and $\rho_{\text {calc }}(\nu)$ is the electron-density map calculated using $F_{\text {calc }}$ amplitudes and $\varphi_{\text {calc }}$ phases of the refined model at a voxel $v$ within the volume pertaining to that atom, $V_{\text {atom }}$. This metric is the weighted average of the electron-density loss over all voxels $V_{\text {atom }}^{-}$in the vicinity of that atom which have negative values in the difference density map $\left[\rho_{\Delta}(\nu)<0\right]$.

\section{Results}

A cuboid-shaped crystal was used for data collection [Fig. 3(a)] and belonged to space group H32. Similarly to the original structure, which included one additional nucleotide (Huang et al., 2005; McGeehan et al., 2007), each asymmetric unit contained a single DNA strand, which is half of the DNA double strand, and the unit cell thus contained 18 monomers. The crystal had a solvent content of $41 \%$.

To monitor the global damage, $I_{n} / I_{1}$ was plotted as a function of dose, where $I_{n}$ is the weighted average of the average intensities of the resolution shells of a complete data set for dose level $n$ and is calculated from the AIMLESS-output intensities as (Bury, McGeehan et al., 2016)

$$
I_{n}=\frac{\sum_{i=1}^{N_{\text {res }}} \operatorname{Av} I_{(i)} \cdot N_{\text {meas }(i)}}{\sum_{i=1}^{N_{\text {res }}} N_{\text {meas }(i)}}
$$


where $N_{\text {res }}$ is the number of resolution shells in the diffraction pattern, $N_{\text {meas }(i)}$ is the number of observed reflections for resolution shell $i \in\left\{1, \ldots, N_{\text {res }}\right\}$ and $\operatorname{Av} I_{(i)}$ is the average intensity for resolution shell $i$. The normalized intensity $I_{n} / I_{1}$ is plotted against the average DWD (Fig. 4). Due to the datacollection strategy and scaling protocol, the same $60^{\circ}$ wedge of the crystal was irradiated during every sixth data set. Owing to the anisotropic intensity profile and the shape of the beam, irradiating a crystal smaller than the beam resulted in different volumes of the crystal being exposed to the most intense part of the beam for each of these wedges. This caused differences in mean intensities between the sequential data sets for which scaling could not compensate. As shown in Fig. 4(a), the mean intensity decay relative to the first data set shows an oscillatory behaviour. To allow the comparison of similar volume wedges, Fig. 4(b) shows the mean intensities normalized to the mean of the first data set for the same crystal rotation wedge,

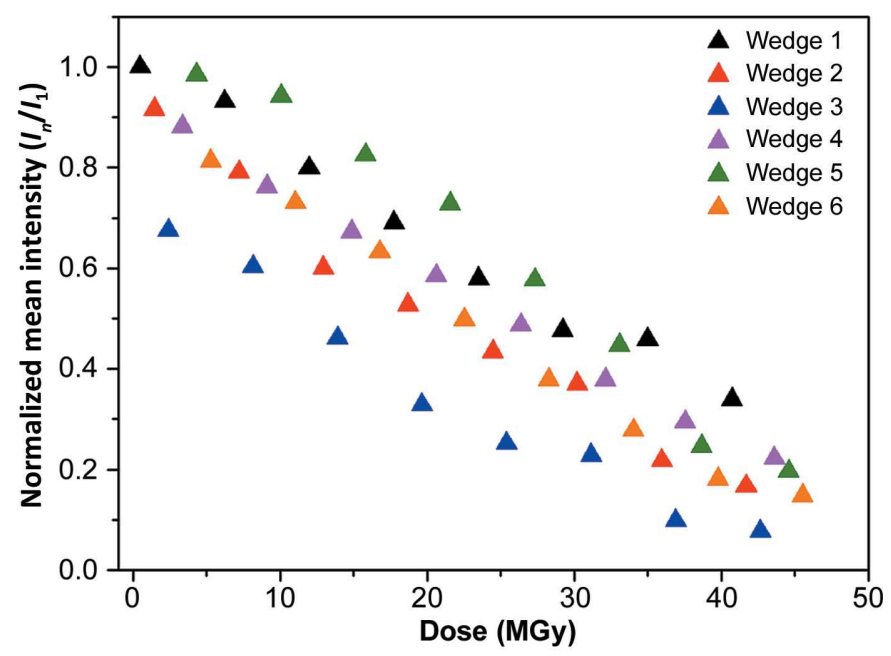

(a)

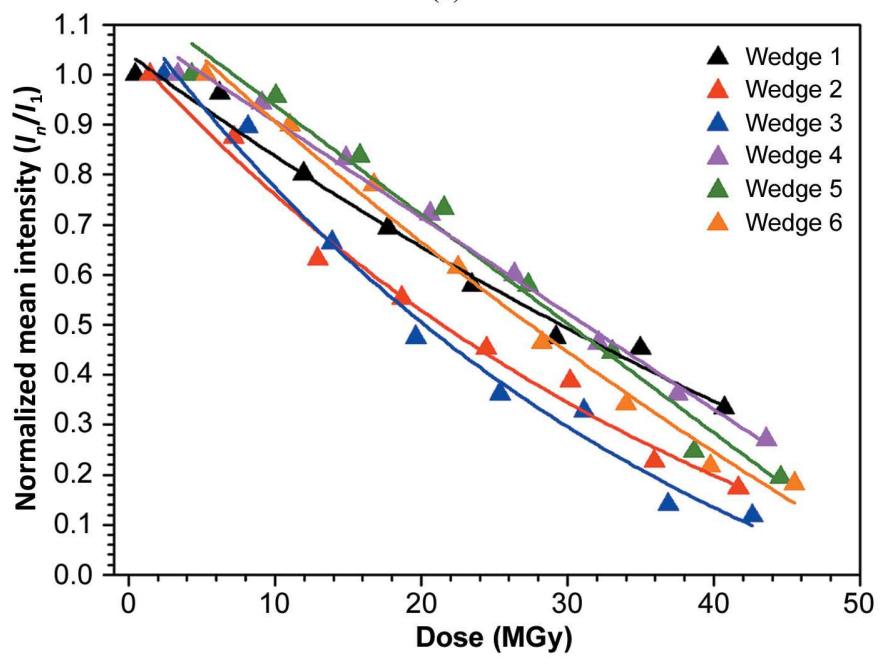

(b)

Figure 4

Mean intensity decay for the 48 DNA data sets $(a)$ normalized to the mean for the first data set and $(b)$ normalized to the mean of the first data set of the same crystal rotation wedge using data sets $1-6$ to normalize the later data sets. The fits shown are exponentials, which all have $R^{2}$ values of $>0.97$.

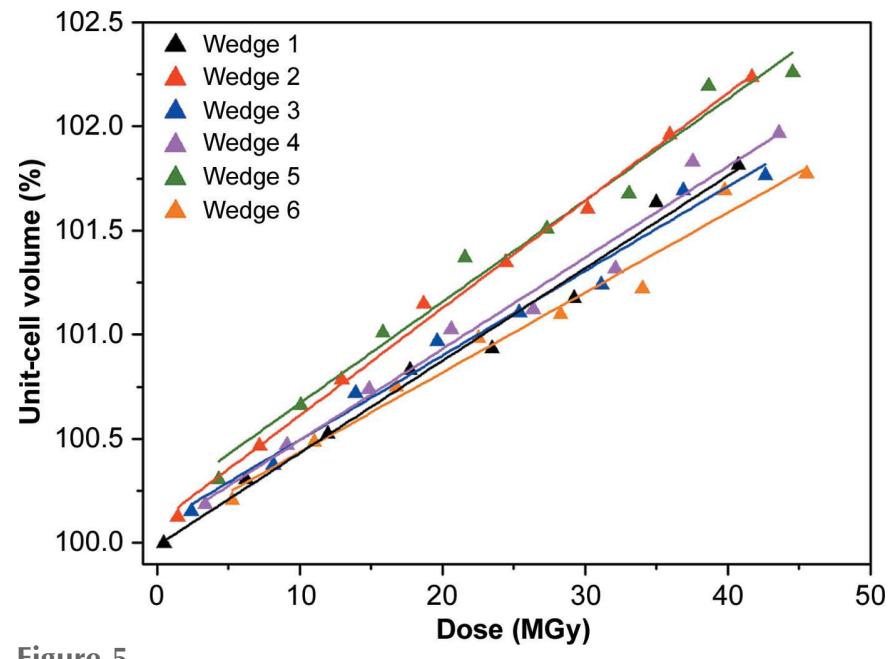

Figure 5

Unit-cell expansion of the DNA crystal. A linear increase with a similar gradient is observed for all rotation wedges over the whole dose range.

using data sets 1-6 to normalize the later data sets. The fits shown are exponentials, which all have $R^{2}$ values of $>0.97$. Averaging all of the resulting gradients results in a $D_{1 / 2}$ of $18.9( \pm 2.6) \mathrm{MGy}$ for all data to $1.8 \AA$ resolution. The two native lysozyme crystals irradiated as controls gave an average $D_{1 / 2}$ of $9.1 \mathrm{MGy}$ (data not shown) for all data to $1.4 \AA$ resolution.

Unit-cell expansion can also be detected for the DNA 16mer crystal and it continues to increase linearly up to the highest dose measured (45.5 MGy; Fig. 5), in contrast to some previous results for protein crystals in which the increase was linear at low dose but then plateaued at higher doses [see, for example, Fig. 1(b) in Garman (2010) for holoferritin crystals above $30 \mathrm{MGy}$ ]. There is a loss of diffraction resolution from 1.8 to $1.96 \AA$ starting at the 14 th data set (above $12.5 \mathrm{MGy}$ ) and falling to $2.6 \AA$ at $35.0 \mathrm{MGy}$. In addition, $R_{\text {meas }}$ increases from the 14th data set onwards.

Another common metric used to monitor radiation damage at $100 \mathrm{~K}$ is the relative isotropic $B$ factor $\left(B_{\mathrm{rel}}\right)$, which is linearly dependent on dose (Kmetko et al., 2006). This is defined as the difference in Wilson $B$ factor between the $n$th data set and the first data set $\left(B_{\text {rel }}=B_{n}-B_{1}\right)$, and its behaviour with dose is shown in Figs. 6(a) and 6(b), where the normalization is as in Fig. 4. Fig. 6(a) shows $B_{\text {rel }}=B_{n}-B_{1}$ calculated for the 48 data sets and Fig. $6(b)$ presents $B_{\text {rel }}$ for the six wedges separated [i.e. $B_{\mathrm{rel}}=B_{(6 m+i)}-B_{i}$, where $m$ is $0-7$ and $i$ is 1-6] normalized to the mean of the first data set of the same crystal rotation wedge, using data sets 1-6 to normalize the later data sets. The relative $B$ factors can be interpreted as being proportional to the change in the meansquared atomic displacements. Since in our case the $I_{n} / I_{1}$, the unit-cell volume and $B_{\text {rel }}$ metrics all showed a dependence on the particular crystal rotation wedge, for analysing specific radiation damage the results from only the first wedge are discussed in detail.

$F_{\mathrm{obs}, n}-F_{\mathrm{obs}, 1}$ difference electron densities were compared and analysed for data sets $n=7,13,19,25,31$ and 37 (wedge $i=1$ data sets) to characterize specific radiation damage 


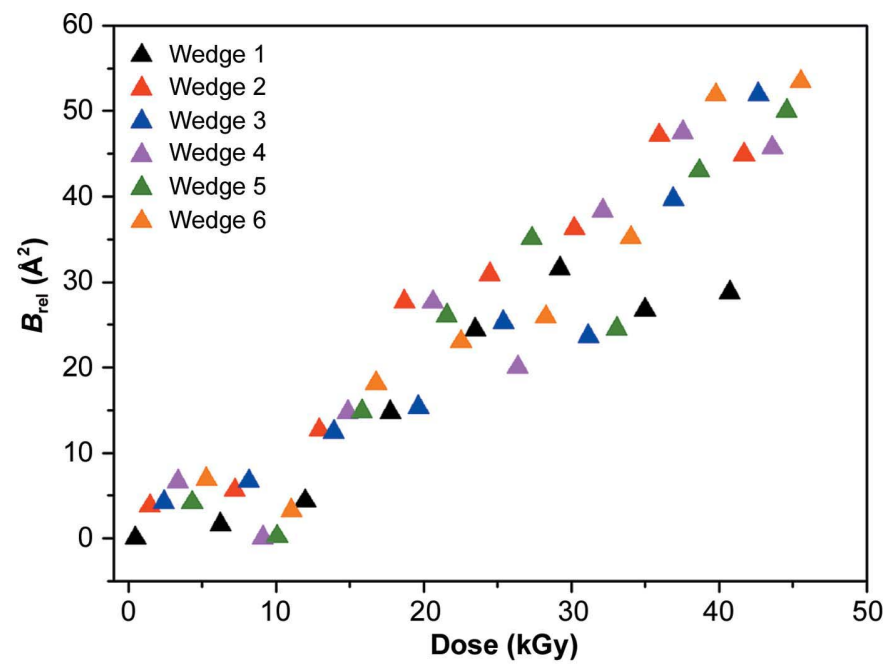

(a)

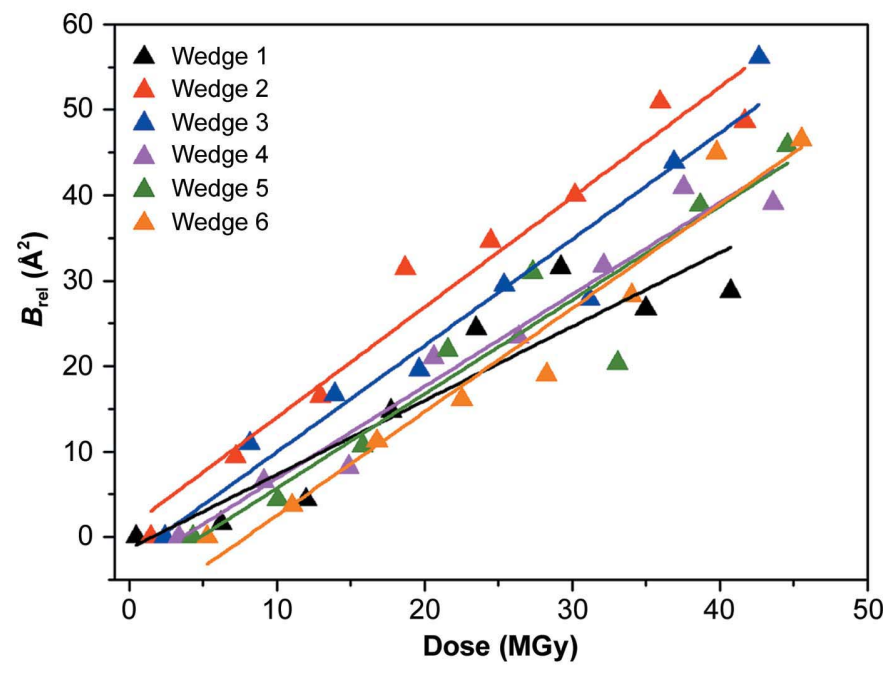

(b)

Figure 6

Relative isotropic $B$ factor for the DNA crystal. A linear increase is observed with increasing dose over the reported dose range. $B_{\text {rel }}=B_{n}-$ $B_{1}$ calculated ( $a$ ) for the 48 data sets and $(b)$ for the six wedges separated [i.e. $B_{\text {rel }}=B_{(6 m+i)}-B_{i}$, where $m$ is $0-7$ and $i$ is 1-6] and normalized to the mean of the first data set of the same crystal rotation wedge, using data sets 1-6 to normalize the later data sets.

indicated by local electron-density changes (Fig. 7). For the refined models created from the higher-dose data sets (i.e. a dose greater than the first data set), the resolution of the electron-density map decreased, and Fourier ripples appeared around calcium ions sitting on the crystallographic threefold axis. The largest changes in electron density are at and around some of the calcium ions $\left[\mathrm{Ca}^{2+}(1), \mathrm{Ca}^{2+}(2), \mathrm{Ca}^{2+}(3)\right.$ and $\mathrm{Ca}^{2+}(4)$, as depicted in Fig. 1(b)] and some of the phosphate moieties (those of the fifth, sixth and 14th-17th nucleotide residues), all of which are involved in the water-mediated hydrogen-bond network (Supplementary Fig. S1). At higher doses, smaller electron-density changes were observed at the heterocyclic moieties. In contrast, nucleotide residues 8-13, which form a more flexible region owing to a lack of any crystallographic contacts, show no significant electron-density changes and neither do similarly located ordered calcium ions, even at very high dose.
Fig. 8 details the distribution of specific damage detected using $R I D L$ throughout the overall structure for every sixth data set. The RIDL $D_{\text {neg }}$ (atom) analysis (see Section 2) also shows that the average electron-density change of calcium ions is larger than that of nucleotide atoms (Fig. 8). The $D_{\text {neg }}$ (atom) and top damage sites (Fig. 10), both derived from the $F_{\mathrm{obs}, n}-F_{\mathrm{obs}, 1}$ maps, show that there are differences in the rates of electron-density change amongst the six calcium ions and their environments. At a dose of $6.2 \mathrm{MGy}$ only $\mathrm{Ca}^{2+}(1)$ is damaged (it is apparently reduced since the electron-density changes are positive as shown in Supplementary Fig. S2), while at $12.0 \mathrm{MGy}$ this and the other two calcium ions sitting on the threefold axis $\left[\mathrm{Ca}^{2+}(2)\right.$ and $\left.\mathrm{Ca}^{2+}(3)\right]$ also show significant electron-density changes $(> \pm 3 \sigma)$. Smaller changes are seen in the vicinity of $\mathrm{Ca}^{2+}(4)$ above $12 \mathrm{MGy}$, and $\mathrm{Ca}^{2+}(5)$ and $\mathrm{Ca}^{2+}(6)$ show only minor changes across the whole dose range (Supplementary Fig. S2).

$R I D L$ additionally flags up damage sites in the vicinity of the phosphorus-oxygen and oxygen-sugar bonds (see Fig. 7). The guanine moieties are slightly more damaged than the other three nucleotides, as is also observed in EPR experiments (Becker et al., 2007), and thymine shows the least density loss. All four nucleotide types suffered radiation damage at fairly similar rates, differences becoming particularly noticeable at the higher doses ( $>24 \mathrm{MGy}$ ). It should be noted, however, that in this small oligonucleotide there are only four nucleotides of each type. Thus, the average characteristics found here could easily be distorted by local interactions specific to this structure. Fig. 9 shows the normalized frequencies of $D_{\text {neg }}$ (atom) values.

Analysis of the electron loss per $\AA^{-3}$ with respect to absorbed dose was performed for different components of the structure (nucleotide types, calcium ions and water molecules). The distribution of the top 25 sites at different positions within the structure is shown in Fig. 10 along with the relative change in electron densities (see Supplementary Table S1 for lists of the top 25 sites as a function of dose). At higher dose values these sites are more concentrated at the two ends of the DNA chain, particularly in the vicinity of the correspondingly located calcium ions. In Fig. 11, the key indicates the nearest atom in the DNA to which specific damage has been assigned. It is evident that clear differential specific damage rates are present not only between different nucleotide types but also within a given nucleotide (e.g. guanines in Fig. 10). The top ten electron-loss sites presented in Fig. 11 are all in proximity or directly bound to $\mathrm{Ca}^{2+}$ ions [the $\mathrm{P}$ atoms of nucleotides 7, 8, 15, 16 and 17 , respectively; see Figs. 1(b), 1(c) and 10 for the positions of $\mathrm{Ca}^{2+}$ ions along the nucleotide chain], suggesting that complexed metals of larger atomic number may enhance sensitivity to radiation-induced specific damage in this case (see also Supplementary Table S2). $F_{\mathrm{obs}, n}-F_{\mathrm{obs}, 1}$ electron-density maps indicate the breakage of several $\mathrm{P}-\mathrm{O}$ bonds and relatively few other changes. For instance, there are small levels of electron-density loss at the aromatic groups and at $\mathrm{C}-\mathrm{O}$ bonds (Fig. 7) at high doses. In contrast to the outer region of the oligonucleotide, the region between nucleotides 9-14 is neither bridged to (ordered) 

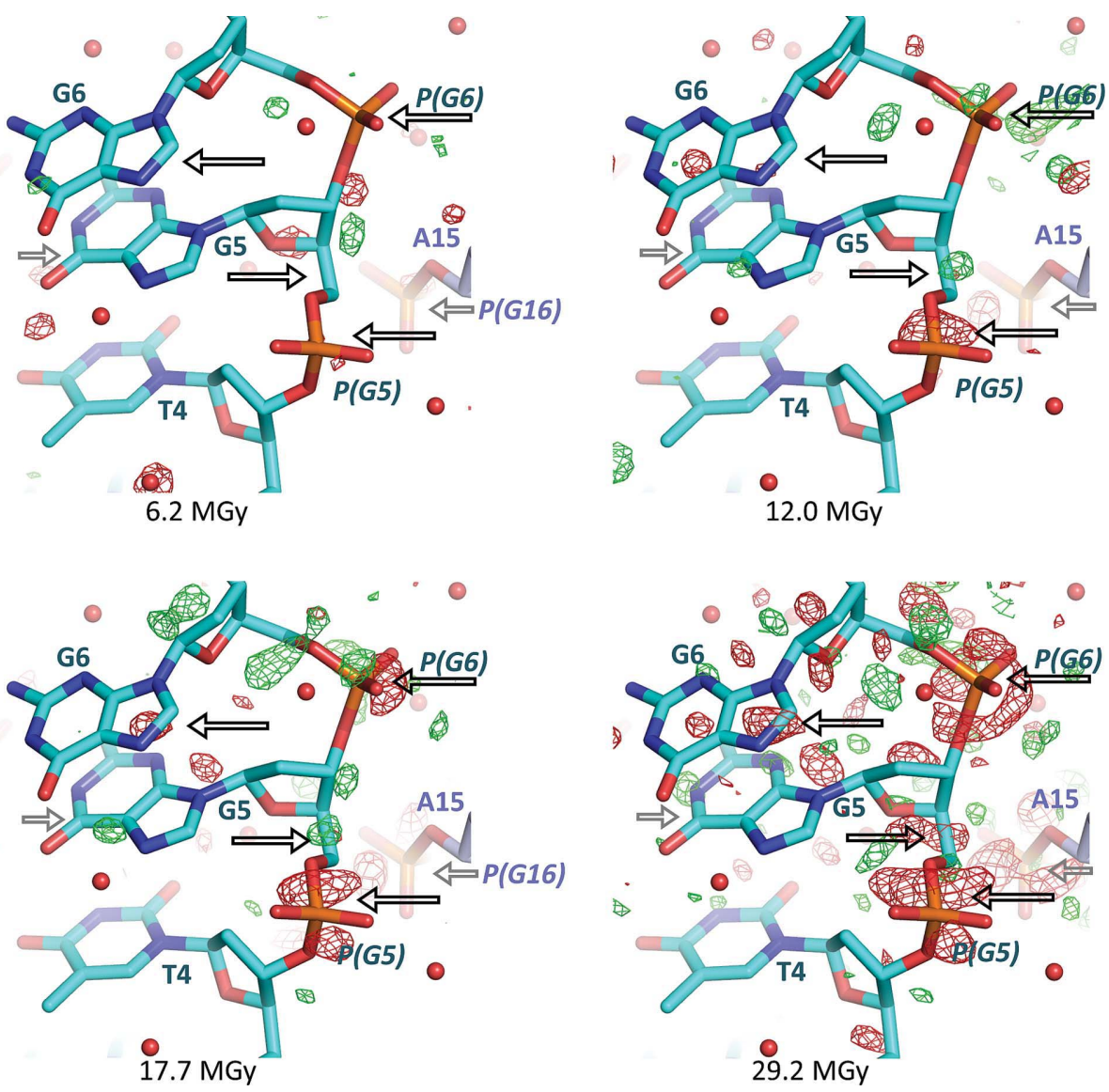

Figure 7

Difference electron-density maps calculated by FFT through the $R I D L$ pipeline $\left(F_{\text {obs }, n}-F_{\text {obs }, 1}\right.$-type maps) contoured for the seventh, 13th, 19th and 31st data sets at 3.0 $\sigma$ and $-3.0 \sigma$ levels in green and red, respectively. Electron-density loss around the phosphate moieties of nucleotides G5 and G6 indicates the occurrence of $\mathrm{P}-\mathrm{O}$ and $\mathrm{C}-\mathrm{O}$ bond breaks, while the aromatic groups show only minor changes in electron density (arrows). Atoms are shown as follows: carbon, sky blue for the DNA chain; phosphorus, orange; oxygen, red; nitrogen, dark blue. Nucleotides are labelled with one-letter codes. P atoms are labelled in italics.

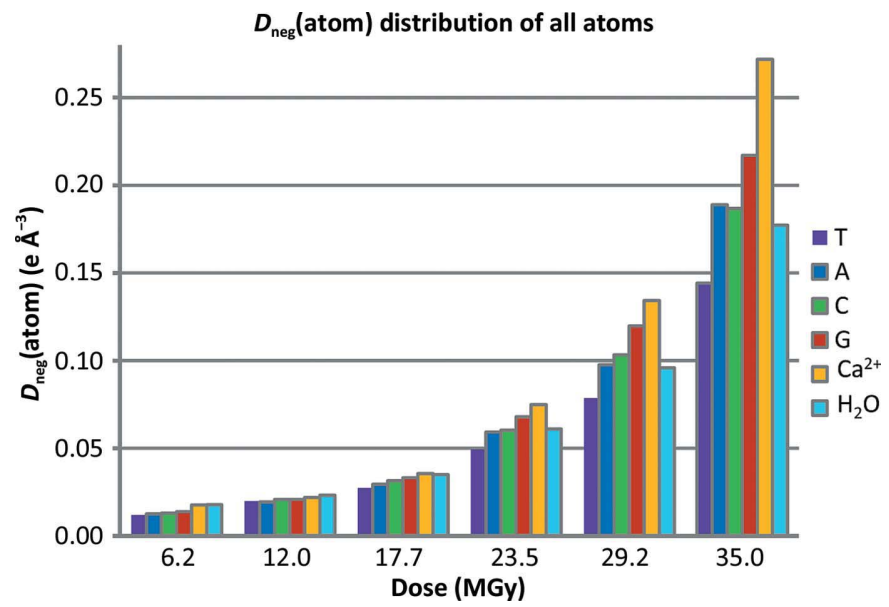

Figure 8

Detected specific damage for each nucleotide type for every sixth data set (data sets $7,13,19,25,31$ and 37 ). $D_{\text {neg }}$ (atom) values averaged for all atoms of each component type indicate the amount of electron-density loss with increasing dose. The oligonucleotides, calcium ions and water molecules are labelled $\mathrm{A}, \mathrm{C}, \mathrm{G}, \mathrm{T}, \mathrm{Ca}^{2+}$ and $\mathrm{H}_{2} \mathrm{O}$, respectively. calcium ions nor establishes intermolecular contacts with other double helices in the crystal. The metrics described above indicate that this region seems to be less prone to radiation damage.

The rate of damage to the different $\mathrm{P}$ atoms in the DNA structure was not uniform, with large variations in the apparent susceptibility. At a dose of 6.2 MGy the $F_{\text {obs }, n}-F_{\text {obs, } 1}$ map shows significant electron-density change $(> \pm 3 \sigma)$ for the $\mathrm{P}$ atoms of only three nucleotides $(5,15$ and 16$)$, at $12.0 \mathrm{MGy}$ at four nucleotides $(5,7,15$ and 16$)$ and at 17.7 MGy at six nucleotides (5-7 and 15-17). Further $\mathrm{P}$ atoms (nucleotides 8, 9 and 11) start to show electron-density changes only at $35.0 \mathrm{MGy}$, whereas those in nucleotides $3,4,10,12,13$ and 14 show no changes above $\pm 3 \sigma$ at this dose. Examples of electron-density changes around the $\mathrm{P}$ atoms of nucleotides 5, 6 and 16 are shown in Fig. 7.

In a crystal of a protein-oligonucleotide complex (C.Esp1396I proteinDNA) it was shown that DNA has a relatively high resistance to specific damage, since the onset of specific damage was detected at significantly larger dose values than for the protein residues in crystals (Bury et al., 2015). In that study, the normalized frequency of DNA nucleotides involved in specific radiation damage reached 0.2 at a dose of about $35 \mathrm{MGy}$. In contrast, similar frequency values for susceptible protein

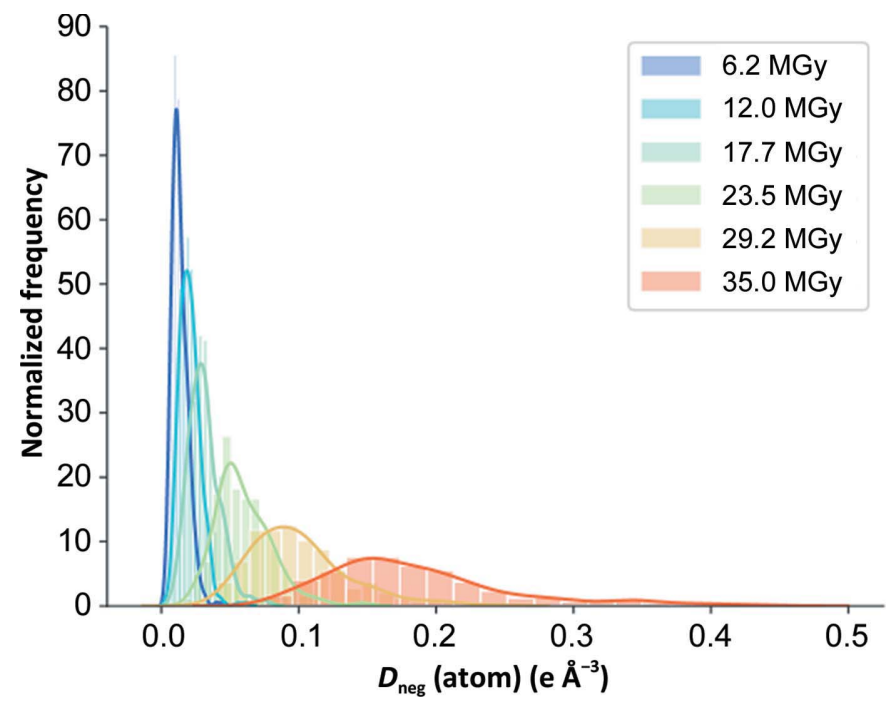

Figure 9

Histogram of $D_{\text {neg }}$ (atom) for data sets $7,13,19,15,31$ and 37. 


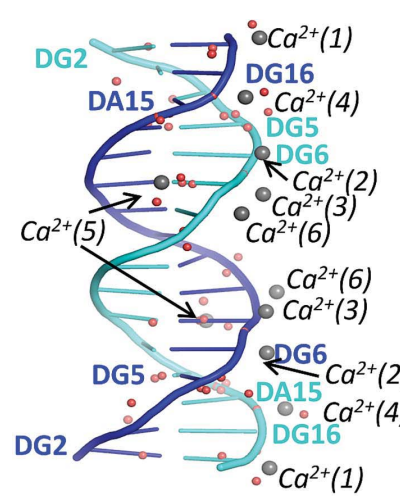

Dose: $0.48 \mathrm{MGy}$

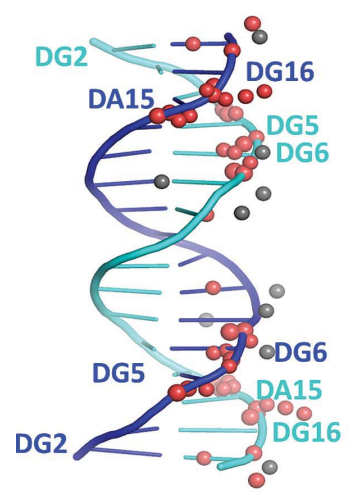

Dose: 17.7 MGy

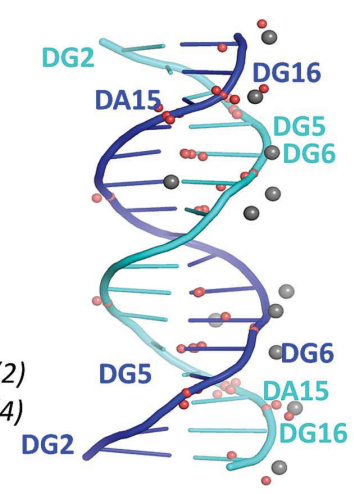

Dose: $6.2 \mathrm{MGy}$

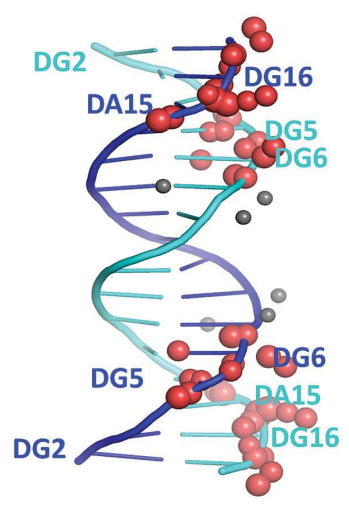

Dose: 23.5 MGy

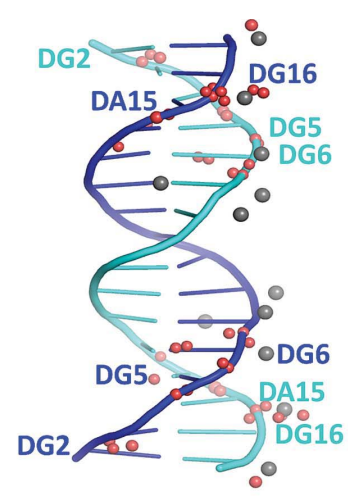

Dose: $12.0 \mathrm{MGy}$

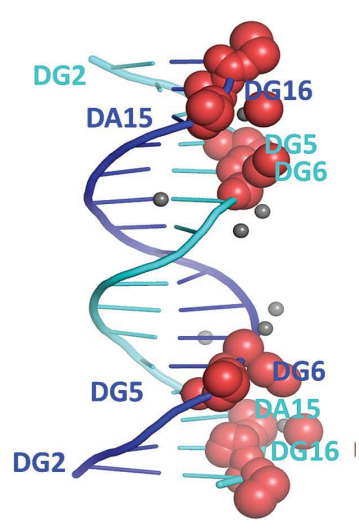

Dose: 29.2 MGy

Figure 10

Representation of the top 25 specific damage sites on each of the two DNA strands (50 in total) at different doses. Specific damage sites are represented as red spheres, with radii proportional to the electron-density loss. $\left(\mathrm{Ca}^{2+}\right.$ ions are shown as grey spheres and the nucleotide residues that are most affected, as well as the first residue G2, are labelled.)

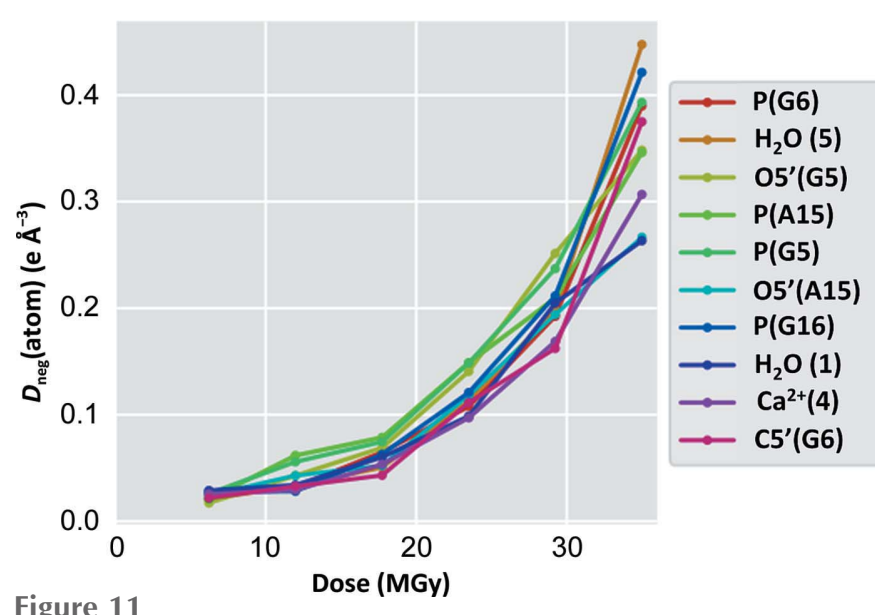

Figure 11

DNA damage of nucleotides, including base-sugar bond, sugarphosphate bond and water-phosphate bond loss. $D_{\text {neg }}$ (atom) values are shown for the top ten radiation-damage sites. [See Figs. 1(b) and 10 for the locations of these sites in the DNA chains.]

residue types were at a dose of about 10 MGy (Bury et al., 2015). For the current DNA 16-mer crystal, we observed very similar resistance: the normalized frequency of DNA nucleotides involved in specific radiation damage reaches 0.2 at 35.0 MGy.
The average atomic $B$ factors for the seven refined structures were analysed and were normalized to the value for the structure derived from data set $n=1$ (Supplementary Fig. S3). They showed a linear increase with dose with a gradient of $0.007 \mathrm{MGy}^{-1}$, which can be compared with values of $0.0041 \mathrm{MGy}^{-1}$ for both DNA strands in the bacterial protein-DNA complex (C.Esp1396I-DNA; Bury et al., 2015).

\section{Discussion}

This radiation-damage study at $100 \mathrm{~K}$ on a crystal of a DNA 16-mer diffracting to $1.8 \AA$ resolution showed that, for this example, DNA alone is somewhat more robust to global radiation damage than the lysozyme used here as a control and which was irradiated under the same beam conditions. This conclusion comes with the proviso that any scavenging capacity of cryo-buffers etc. was comparable. The $D_{1 / 2}$ for the $1.8 \AA$ resolution DNA 16-mer crystal data was 18.9 ( \pm 2.6$)$ MGy (an average for all six series of eight data sets each \pm standard deviation) compared with $9 \mathrm{MGy}$ for the lysozyme control for $1.4 \AA$ resolution data. There are various $D_{1 / 2}$ values in the literature for native lysozyme crystals (no explicit scavengers added) examined at $100 \mathrm{~K}$, among them being two studies on several crystals each: 17 MGy for all data to $1.6 \AA$ (Teng \& Moffat, 2002), and 12.5-12.9 MGy for all resolution shells to $1.7 \AA$ (de la Mora et al., 2011). These values were obtained using rather different dose estimation methods, but both indicate the comparative radiation sensitivity of lysozyme. In comparison, the $D_{1 / 2}$ for the C.Esp1396I protein-DNA complex was $43 \mathrm{MGy}$ (DWD) for all data to $2.8 \AA$ resolution; see the supporting information of Bury et al. (2015); the same value was obtained for all data to $2.2 \AA$ resolution for holoferritin and apoferritin using a beam with a top-hat profile bigger than the crystal giving homogeneous irradiation (Owen et al., 2006).

We have also demonstrated that for the DNA 16-mer crystal the relative isotropic $B$ factor, $B_{\text {rel }}$, varies very linearly with increasing dose over the whole of the reported dose range (Fig. 5) without a plateau at high doses as has been observed for some protein crystals [see, for example, Fig. $1(d)$ in Garman (2010)]. The coefficient of sensitivity (Kmetko et al., 2006), $s_{\mathrm{AD}}=\Delta B_{\text {rel }} / 8 \pi^{2} \Delta D$, is $0.014 \AA^{2} \mathrm{MGy}^{-1}$, which is similar to the average value of $0.012 \AA^{2} \mathrm{MGy}^{-1}$ determined for four protein crystals at $100 \mathrm{~K}$ (lysozyme, thaumatin, catalase and apoferritin; Kmetko et al., 2006), indicating that according to this metric the DNA in the crystal suffers comparable rates of damage to that of protein crystals. 
The unit-cell volume expansion noted for the DNA crystal here is in the same range as is observed for proteins (Fig. 5), being about $1.5 \%$ for $30 \mathrm{MGy}$. However, for crystals of the same protein it shows great variability, but for instance has been reported to be around $2 \%$ in crystals of holoferritin at a dose of 30 MGy (Garman, 2010).

The average atomic $B$ factors of the refined models of the DNA 16-mer increase from 49 to $58 \AA^{2}$ over the dose range studied, a gradient of $0.29 \AA^{2} \mathrm{MGy}^{-1}\left(8.4 \AA^{2}\right.$ in $\left.28.7 \mathrm{MGy}\right)$, which if normalized to the average $B$ factor for the lowestdose data set gives a change with dose of $0.007 \mathrm{MGy}^{-1}$ (see Supplementary Fig. S1). In the C.Esp1396I protein-DNA complex study (Bury et al., 2015), the normalized (to unity for the lowest dose) atomic $B$-factor DNA gradient was $0.004 \mathrm{MGy}^{-1}$ compared with the gradient for the protein of around $0.006 \mathrm{MGy}^{-1}$, which is very close to that found here for the DNA alone. In that work, thymine was reported to be slightly more damaged than the other bases, with guanine being the least affected, in contrast to the finding here of preferential damage to guanine in the crystal of DNA alone. As already mentioned, the results of Bury and coworkers showed that the onset of specific damage is at significantly higher doses for DNA than for protein within the C.Esp1396I protein-DNA complex, and that when it does occur specific damage is more evenly distributed between the four base types than it is amongst the protein residues.

Using the innovative, highly streamlined and automated $R I D L$ pipeline for the identification of X-ray-induced structural damage patterns, we have established the existence of differential specific damage rates with respect to dose at $100 \mathrm{~K}$ in a DNA 16-mer crystal. The RIDL tool removed the requirement for manual inspection of $F_{\mathrm{obs}, n}-F_{\mathrm{obs}, 1}$ maps and outputs metrics that have been explicitly designed to objectively characterize site-specific radiation damage to atoms (Bury, McGeehan et al., 2016).

The site-specific damage to the DNA 16-mer studied here is primarily located on the phosphates. The chemical nature and mechanism of this 'phosphate' damage was not investigated in this study, but we hypothesize that it involves $\mathrm{P}-\mathrm{O}$ and/or $\mathrm{O}-$ sugar bond breakage. Indeed, sophisticated electronic structure calculations have suggested a mechanism by which the latter linkage, in particular, may be broken by low-energy electrons (Simons, 2007). Increased phosphate freedom can produce a displacement, and thus lead to changes in negative density in OMIT maps. This phosphate displacement could also explain the loss of density around one of the phosphate $\mathrm{O}$ atoms at high doses. We note that owing to the greater X-ray cross-section of the DNA compared with the $41 \%$ solvent by volume, more ionizations will occur in the DNA than in its surroundings. The sensitivity of the structure to specific radiation damage was lowest in the region of the aromatic groups of the nucleobases and highest at the phosphate moieties. As noted above, guanine was the most damaged base, presumably acting as a hole trap owing to its relatively low ionization potential (Jovanovic \& Simic, 1986; Becker et al., 2007).
Using a metric calculated by RIDL and comparing segments coordinating and lacking calcium ions, we showed that the occurrence of electron-density loss is highest in the vicinity of certain calcium ions in the structure. Since only some of these ions are damaged, this is clearly not a direct effect of the larger X-ray photon-absorption cross-section of these heavy ions. Furthermore, as there are calciumcomplexed and noncomplexed DNA segments in the structure, the radiation sensitivity of these could be directly compared.

The results of this experiment suggested that, interestingly, the differential sensitivity to damage among the various phosphates as detailed in the results was far greater than that observed among disulfide bonds in protein crystals [for example, for lysozyme all four disulfide bonds show damage by a dose of $0.14 \mathrm{MGy}$, as shown in Fig. 6 of Sutton et al. (2013)]. The fact that we observed differential damage to the phosphates presumably indicates again that the damage was not solely direct.

The radiation tolerance of DNA crystals should be investigated further by pursuing experiments focused on a range of crystals containing DNA segments of different lengths, and if possible in the absence of bound heavy atoms. It would be particularly interesting to study DNA in complex with the radiosensitizing drug cisplatin, since its synergistic effects are used extensively to enhance the effects of radiotherapy for cancer treatment [see, for example, Marcu et al. (2003) and Fayette et al. (2015) for a review, and Fayette et al. (2015) for a treatment-regime comparison] and the underlying mechanisms of this are poorly understood.

\section{Acknowledgements}

The authors would like to thank Selina Storm and Danny Axford at DLS for their advice and assistance on I24 during X-ray data collection, Joshua Dickerson for help with $R A D D O S E-3 D$, Edward Lowe for assistance with data processing and Charlie Bury for his constructive comments on the manuscript.

\section{Funding information}

A short-term EMBO fellowship (VB), which provided the opportunity for collaboration on this project, is gratefully acknowledged. The research of $\mathrm{VH}$ within project No. VEKOP-2.3.3-15-2017-00018 was supported by the European Union and the State of Hungary, co-financed by the European Regional Development Fund. IC is supported by the US Department of Energy Office of Science, Office of Basic Energy Sciences under Award No. DE-FC02-04ER15533.

\section{References}

Alizadeh, E., Orlando, T. M. \& Sanche, L. (2015). Annu. Rev. Phys. Chem. 66, 379-398.

Alizadeh, E. \& Sanche, L. (2014). Eur. Phys. J. D, 68, 97. 
Becker, D., Adhikary, A. \& Sevilla, M. D. (2007). Charge Migration in DNA: Perspectives from Physics, Chemistry, and Biology, edited by T. Chakraborty, pp. 139-175. Berlin, Heidelberg: Springer.

Becker, D. \& Sevilla, M. D. (1993). DNA and Chromatin Damage Caused by Radiation, edited by J. T. Lett \& W. K. Sinclair, pp. 121180. San Diego: Academic Press.

Berman, H. M., Westbrook, J., Feng, Z., Gilliland, G., Bhat, T. N., Weissig, H., Shindyalov, I. N. \& Bourne, P. E. (2000). Nucleic Acids Res. 28, 235-242.

Boudaïfa, B., Cloutier, P., Hunting, D., Huels, M. A. \& Sanche, L. (2000). Science, 287, 1658-1660.

Brockhauser, S., Di Michiel, M., McGeehan, J. E., McCarthy, A. A. \& Ravelli, R. B. G. (2008). J. Appl. Cryst. 41, 1057-1066.

Burmeister, W. P. (2000). Acta Cryst. D56, 328-341.

Bury, C., Garman, E. F., Ginn, H. M., Ravelli, R. B. G., Carmichael, I., Kneale, G. \& McGeehan, J. E. (2015). J. Synchrotron Rad. 22, 213224.

Bury, C. S., Carmichael, I. \& Garman, E. F. (2017). J. Synchrotron Rad. 24, 7-18.

Bury, C. S., Carmichael, I., McGeehan, J. E. \& Garman, E. F. (2016). Radiat. Phys. Chem. 128, 118-125.

Bury, C. S. \& Garman, E. F. (2018). J. Appl. Cryst. 51, 952-962.

Bury, C. S., McGeehan, J. E., Antson, A. A., Carmichael, I., Gerstel, M., Shevtsov, M. B. \& Garman, E. F. (2016). Acta Cryst. D72, 648657.

Cadet, J., Delatour, T., Douki, T., Gasparutto, D., Pouget, J.-P., Ravanat, J.-L. \& Sauvaigo, S. (1999). Mutat. Res. 424, 9-21.

De la Mora, E., Carmichael, I. \& Garman, E. F. (2011). J. Synchrotron Rad. 18, 346-357.

Emsley, P., Lohkamp, B., Scott, W. G. \& Cowtan, K. (2010). Acta Cryst. D66, 486-501.

Evans, P. (2006). Acta Cryst. D62, 72-82.

Evans, P. R. \& Murshudov, G. N. (2013). Acta Cryst. D69, 1204-1214.

Fayette, J., Molin, Y., Lavergne, E., Montbarbon, X., Racadot, S., Poupart, M., Ramade, A., Zrounba, P., Céruse, P. \& Pommier, P. (2015). Drug. Des. Dev. Ther. 9, 6203-6210.

Garman, E. F. (2010). Acta Cryst. D66, 339-351.

Garman, E. F. \& Owen, R. L. (2006). Acta Cryst. D62, 32-47.

Garman, E. F. \& Weik, M. (2017). Methods Mol. Biol. 1607, 467-490.

Halliwell, B. \& Gutteridge, J. M. C. (1998). Free Radicals in Biology and Medicine, 3rd ed. Oxford University Press.

Helliwell, J. R. (1988). J. Cryst. Growth, 90, 259-272.

Holton, J. M. (2009). J. Synchrotron Rad. 16, 133-142.

Howells, M. R., Beetz, T., Chapman, H. N., Cui, C., Holton, J. M., Jacobsen, C. J., Kirz, J., Lima, E., Marchesini, S., Miao, H., Sayre, D. S., Shapiro, D. A., Spence, J. H. C. \& Starodub, D. (2009). J. Electron Spectrosc. Relat. Phenom. 170, 4-12.

Huang, D. B., Phelps, C. B., Fusco, A. J. \& Ghosh, G. (2005). J. Mol. Biol. 346, 147-160.

Jovanovic, S. V. \& Simic, M. G. (1986). J. Phys. Chem. 90, 974-978.

Kadhim, M. A., Hill, M. A. \& Moore, S. R. (2006). Radiat. Prot. Dosimetry, 122, 221-227.

Kempner, E. S. (1993). Q. Rev. Biophys. 26, 27-48.

Kmetko, J., Husseini, N. S., Naides, M., Kalinin, Y. \& Thorne, R. E. (2006). Acta Cryst. D62, 1030-1038.

Marcu, L., van Doorn, T. \& Olver, I. (2003). Acta Oncol. 42, 315-325.

Matsui, Y., Sakai, K., Murakami, M., Shiro, Y., Adachi, S., Okumura, H. \& Kouyama, T. (2002). J. Mol. Biol. 324, 469-481.

McCoy, A. J., Grosse-Kunstleve, R. W., Adams, P. D., Winn, M. D., Storoni, L. C. \& Read, R. J. (2007). J. Appl. Cryst. 40, 658-674.

McGeehan, J. E., Carpentier, P., Royant, A., Bourgeois, D. \& Ravelli, R. B. G. (2007). J. Synchrotron Rad. 14, 99-108.
Michael, B. D. \& O'Neill, P. (2000). Science, 287, 1603-1604.

Murshudov, G. N., Skubák, P., Lebedev, A. A., Pannu, N. S., Steiner, R. A., Nicholls, R. A., Winn, M. D., Long, F. \& Vagin, A. A. (2011). Acta Cryst. D67, 355-367.

Nave, C. \& Garman, E. F. (2005). J. Synchrotron Rad. 12, 257-260.

O'Neill, P., Stevens, D. L. \& Garman, E. (2002). J. Synchrotron Rad. 9, 329-332.

Owen, R. L., Axford, D., Nettleship, J. E., Owens, R. J., Robinson, J. I., Morgan, A. W., Doré, A. S., Lebon, G., Tate, C. G., Fry, E. E., Ren, J., Stuart, D. I. \& Evans, G. (2012). Acta Cryst. D68, 810818.

Owen, R. L., Holton, J. M., Schulze-Briese, C. \& Garman, E. F. (2009). J. Synchrotron Rad. 16, 143-151.

Owen, R. L., Rudiño-Piñera, E. \& Garman, E. F. (2006). Proc. Natl Acad. Sci. USA, 103, 4912-4917.

Potterton, L., Agirre, J., Ballard, C., Cowtan, K., Dodson, E., Evans, P. R., Jenkins, H. T., Keegan, R., Krissinel, E., Stevenson, K., Lebedev, A., McNicholas, S. J., Nicholls, R. A., Noble, M., Pannu, N. S., Roth, C., Sheldrick, G., Skubak, P., Turkenburg, J., Uski, V., von Delft, F., Waterman, D., Wilson, K., Winn, M. \& Wojdyr, M. (2018). Acta Cryst. D74, 68-84.

Ptasińska, S. \& Sanche, L. (2007). Phys. Rev. E, 75, 031915.

Ravelli, R. B. G. \& Garman, E. F. (2006). Curr. Opin. Struct. Biol. 16, 624-629.

Ravelli, R. B. G. \& McSweeney, S. M. (2000). Structure, 8, 315-328.

Sauter, N. K., Hattne, J., Grosse-Kunstleve, R. W. \& Echols, N. (2013). Acta Cryst. D69, 1274-1282.

Simons, J. (2007). Adv. Quantum Chem. 56, 171-188.

Snell, E. H., Bellamy, H. D., Rosenbaum, G. \& van der Woerd, M. J. (2007). J. Synchrotron Rad. 14, 109-115.

Spotheim-Maurizot, M. \& Davídková, M. (2011). Mutat. Res. 711, 4148.

Sutton, K. A., Black, P. J., Mercer, K. R., Garman, E. F., Owen, R. L., Snell, E. H. \& Bernhard, W. A. (2013). Acta Cryst. D69, 23812394.

Swarts, S. G., Gilbert, D. C., Sharma, K. K., Razskazovskiy, Y., Purkayastha, S., Naumenko, K. A. \& Bernhard, W. A. (2007). Radiat. Res. 168, 367-381.

Taberman, H., Bury, C. S., van der Woerd, M. J., Snell, E. H. \& Garman, E. F. (2019). J. Synchrotron Rad. 26, 931-944.

Teng, T. \& Moffat, K. (2000). J. Synchrotron Rad. 7, 313-317.

Teng, T.-Y. \& Moffat, K. (2002). J. Synchrotron Rad. 9, 198-201.

Warren, A. J., Axford, D. \& Owen, R. L. (2019). J. Synchrotron Rad. 26, 991-997.

Weik, M., Ravelli, R. B. G., Kryger, G., McSweeney, S., Raves, M. L., Harel, M., Gros, P., Silman, I., Kroon, J. \& Sussman, J. L. (2000). Proc. Natl Acad. Sci. USA, 97, 623-628.

Winn, M. D., Ballard, C. C., Cowtan, K. D., Dodson, E. J., Emsley, P., Evans, P. R., Keegan, R. M., Krissinel, E. B., Leslie, A. G. W., McCoy, A., McNicholas, S. J., Murshudov, G. N., Pannu, N. S., Potterton, E. A., Powell, H. R., Read, R. J., Vagin, A. \& Wilson, K. S. (2011). Acta Cryst. D67, 235-242.

Winter, G., Waterman, D. G., Parkhurst, J. M., Brewster, A. S., Gildea, R. J., Gerstel, M., Fuentes-Montero, L., Vollmar, M., MichelsClark, T., Young, I. D., Sauter, N. K. \& Evans, G. (2018). Acta Cryst. D74, 85-97.

Yokoya, A., Cunniffe, S. M. T. \& O'Neill, P. J. (2002). J. Am. Chem. Soc. 124, 8859-8866.

Zeldin, O. B., Brockhauser, S., Bremridge, J., Holton, J. M. \& Garman, E. F. (2013). Proc. Natl Acad. Sci. USA, 110, 20551-20556.

Zeldin, O. B., Gerstel, M. \& Garman, E. F. (2013). J. Appl. Cryst. 46, 1225-1230. 